\title{
STUDIES AND RESEARCH ON THE BUILDING OF A STABILIZING PLATFORM FOR AERIAL PHOTOGRAMMETRY
}

\author{
NEDEFF, V[alentin]; MOSNEGUTU, E[milian]; JOITA, I[on]; LAZAR, G[abriel]; \\ PAL, A[nton]; SAMOILA, F[lorin] \& CIOBANU, E[lena]
}

\begin{abstract}
Cadastral methods must be as fast and accurate as possible. A method of cadastre is reference to the use the aircraft. Because during a flight can occur diverse external factors that can change the normal flight conditions, can influence respectively pictures from by the camera, it is necessary that it be mounted on a stabilizing platform. Such a platform was designed and built by S.C. Aerostar S.A. Bacau in collaboration with "VasileAlecsandri" University of Bacau. This platform, on three axes, permit the achievement the movements to compensate of the axis system of the aircraft, respectively have been combined two stabilized platforms: a simple one, for motion compensation on an axis (gyration) and a compound one, for compensating movement on the other two axes (the roll and pitch motions). The correction of deviation is performed by the power supply and control units, while the information regarding the aircraft's deviation is provided by the inertial measurement unit.
\end{abstract}

Keywords:photogrammetry, stabilizing platform, platform on three axes

\section{INTRODUCTION}

The traditional systems of topographical measurements and land monitoring cannot provide continuous andaccurate information when needed, as their effort to register and centralize the topographic data takes a very long time.

Even if photogrammetry uses photographs (or digital images) for measurements, this concept was invented by Leonardo da Vinci in 1480 [6], and developed by Albrecht Duerer (1525) and Johan Heinrich Lambert (1759).

The relation between geometric projection and photogrammetry was first studied by R.Sturms and Hauck Guido in Germany, in 1883. In 1837, Mandé Daguerre obtained the first "practical" result in photogrammetry by using a process he called the Daguerreotype [31].

In 1849, AiméLaussedat was the first person which uses the photos terrestrial for elaboration a topographical map [3].

In 1893, Cornele Adams invented a new method - the "Method of Photogrammetry". His approach was to obtain two aerial photos of the same area with a camera from two different positions. In 1911, the Scheimpflug Th., who obtained a rectified photography for the first time, is considered the founder of aerial photogrammetry, since he was the first to successfully use photogrammetric principles in order to get an aerial photograph.

Photogrammetry is an art, a science, a technology that is used to obtain information about physical objects and about the environment, by recording, measuring and interpreting photographicimages [4]. It recently underwent major changes in both the acquisition sensor technology and the exploitation of traditional frames and stereograms.

The results obtained by using photogrammetry can be materialized in [20, 28]:

a.coordinates of an object;

b.topographical lifting and thematic maps;

c.photography rectification.

According to the domain in which it is applied, photogrammetry can be classified into arial photogrammetry (which is especially long-range photogrammetry) and terrestrial photogrammetry (especially the near domain of photogrammetry) [28, 33, 35].

Aerial photogrammetry is mainly used for creating topographic survey, thematic maps and digital terrain models (Fig. 1.) $[7,8,11,13,17,37,40]$. Photogrammetric maps based on modern technologies can be produced by using the GPS (Global Position System) system, which consists of a GPS receiver placed within the aircraft which made the flight,for record continuesposition, and a continuous GPS station (differential GPS), located in the field in order to correct differences and to obtain the best possible trajectory of the aircraft.

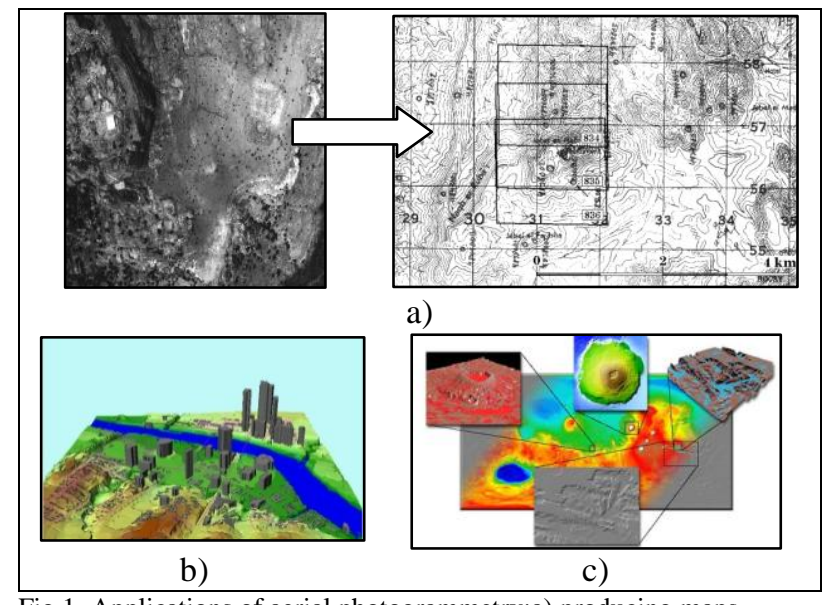

Fig.1. Applications of aerial photogrammetry:a) producing maps, b) producing digital models, c) thematic maps

The necessary equipment for aerial photogrammetry includes $[9,10,12,15,16,21,22,23,29,30,34,36,39$, 43]:

-an aircraft (fig. 2.); 
- camera which can be metric camera, camera stereometry and camera amateur;

- a stabilizing platform.

Because of the external factors which act on airplane, it supports during flight, deviations from the normal flight conditions, called parasitic rotations.

To define the attitude of an aircraft, its movement is related to a CGXYZ three-rectangular axis system, positioned in the center of gravity- CG of the aircraft, with:

- the CGX axis - the rolling axis, that is parallel to the longitudinal axis of the aircraft and is oriented in the direction of the flight;

- $\mathrm{CGY}$ axis - the pitching axis, that is perpendicular to the longitudinal axis and is oriented towards the right wing;

- CGZ axis - the yaw axis, that is perpendicular to the plane formed by the other two axes and is oriented in the direction of the action of gravitational acceleration.

2):

The angles which define the aircraft attitude are (Fig.

- the rolling angle $[\varnothing]$ - the angular deviation of the CGY vertical axis;

- the pitching angle $[\omega]$ - the angular deviation of the CGX vertical axis;

- theyaw angle $[\mathrm{k}]$ - the angular deviation of the CGX horizontal axis.

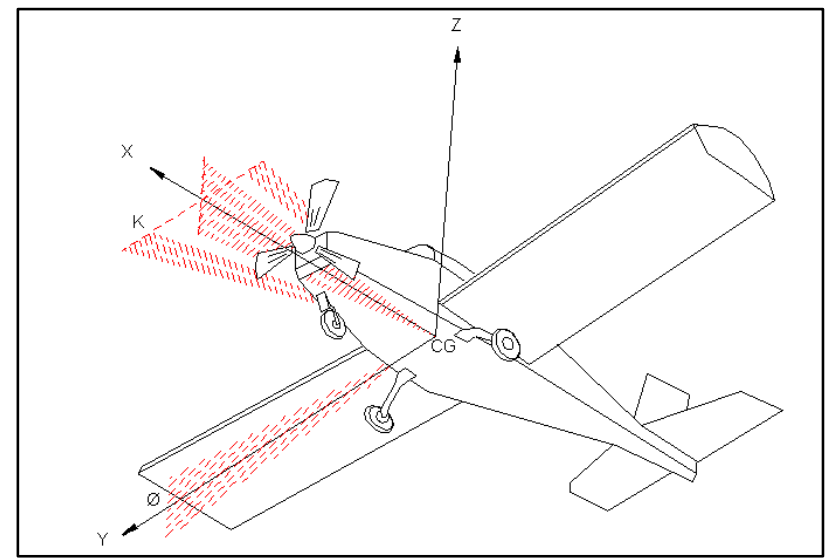

Fig. 2. Aircraft principal axes

The role of the platform is to position the camera and to stabilize its position as related to a reference system [41], taking over the vibrations produced by the aircraft or its sudden deviations from the flight, in order to obtain images which characteristics are kept to a picture to another (Fig. 3).

Depending on the vehicle type, platforms can be used for $[5,15,18,19,21,24,25,26,27,32,42,43]$ :

1. aircrafts;

2. land bases;

3. cars, stabilizing launch platforms;

4. ships;

5. space vehicles;

6. missiles.

The stabilized platforms are inertial and non-inertial stabilization equipment for movement and depending on the number of axles after which undertaking the stabilization they can be one, two or three axes.

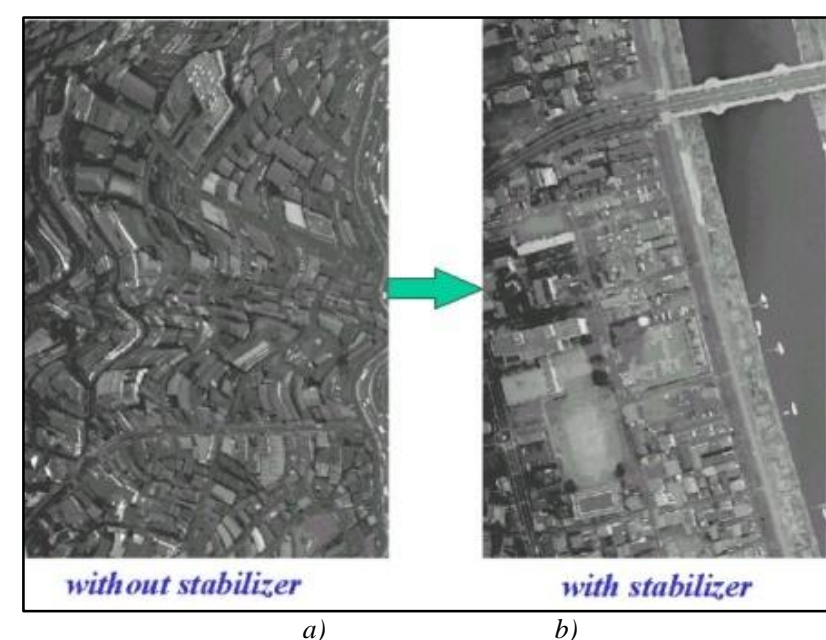

Fig. 3. Image obtained: a) without a stabilizing platform (left) b) with a stabilizing platform (right)

Stabilizing platforms with two or three axes are generally combinations of two or three platforms, each stabilized on one axis and oriented in the direction of their corresponding axes, which are either interconnected or not.

The stabilizing platform for video aerial surveillance equipment (MSTB), as a subassembly of airborne systems for topographic data registration or aerial surveillance, improves the conditions of data collection, ensuring the high accuracy of the information used in map drawing, digital map production and aerial surveillance of the territory. This information processing provides for both individual users with applications in diverse economic structures as well as the national bodies, a modern integrated system of acquisition and use of the data.

Such a stabilizing platform for a small task is mainly destined for aircrafts like UAVs (Unmanned Aerial Vehicle), but it may be also used in land vehicles or river crafts.It can be used for installing a camera on the frame of an airborne craft to record and process topographic spatial data -SADT-01.

Designs of equipment to meet two important criteria (as low weight and easy handling of camera) have been and there are important requirements for components which are attached to aircraft.

From the literature review and taking into account the achievements in this field was adopted, as constructive model, a platform with two linear drive systems and composed bearing ball [1, 2]. This system aims at achieving the motion of platform after three axes. The manner to achieve the movement of platform has the advantage to reduce of his weight.

The stabilizing platform was designed and built by S.C. Aerostar S.A. in collaboration with "VasileAlecsandri" University of Bacau it uses to making the aerial photography. In the future the teams of both institutions will try to improve the performance of this type of platform and minimize his weight 


\section{EQUIPMENT PRESENTATION}

To ensure the institutional consolidation of cadastral activity and property advertising, the new institutions were created under the law 7/1996, regarding the cadastre and property advertising, and in the Emergency Ordinance 41/2004. Consequently, the National Agency for Cadastre and Land (ANCPI) and the National Centre for Geodesy, Cartography, Photogrammetry and Remote Sensing (CNGCFT) were created.

Romania's wish to join the European Union led to the development of "The National Strategy for the Sustainable Development of Romania. 2013-2020-2030". In Part IV, "Romania's Cadastre", subchapter 4.2, it is stated that "Unlike most EU Member States, Romania still lacks a general land register for the whole territory of the country, that should contain complete essential data regarding the delimitation of the administrative-territorial units, of the private properties, of the areas with an economic destination (including real estate and utilities), of buildings, of terrestrial and aquatic ecosystems (including protected areas), of historical sites (including archaeological sites) and of sites that belong to the cultural patrimony."

Therefore "it is estimated that the completion of the national general survey plan based on cadastral index estimates will be possible around 2020" according to "2020. National Objective: The general completion of the national cadastre of Romania and the transparency and accessibility of the system"[14].

To achieve this objective, the database must be updated, in which the photo plans are also included.

For this purpose, S.C. Aerostar S.A., in collaboration with "VasileAlecsandri" University of Bacau, designed and built a stabilizing platform [38].

The airborne platform will consist of an ultra light airplane of the AEROSTAR-01 no. YR-6138 prototype (it is also called "Festival ultra light standard airplane") (Fig. 4).

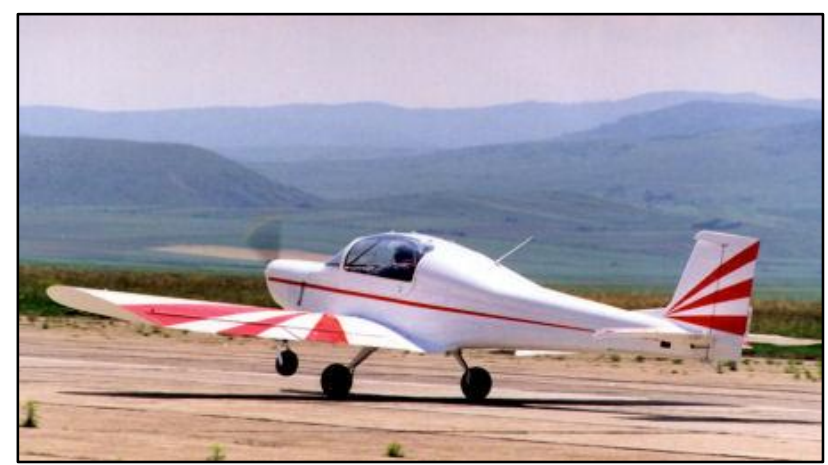

Fig. 11. Photo of the aircraft FESTIVAL [38]

This stabilizing platform is a platform with three axes, conceived as a combination of two platforms: a simple platform for compensation on one axis (yaw) and a compound one for compensation on the other two axes (rolling and pitching) (Fig. 5).

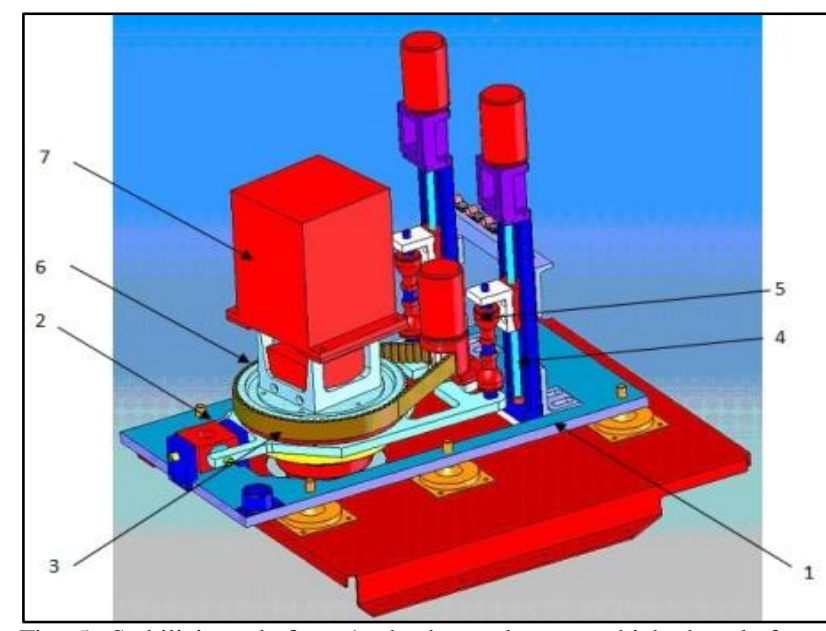

Fig. 5. Stabilizing platform:1. the base plate on which the platform components are mounted; 2 . the stabilizing plate that supports the camera and takes over the linear and rotational motions; 3 . the direction stabilizing plate that rotates the camera so that its position should correspond to the direction of movement; 4 . the linear drives; 5 . the joint; 6 . the camera; 7 . the altitude sensors that detect and measure the movements of the aircraft in the three directions (yaw, pitching and rolling) [38]

Depending on the position of the platform in relation to the axis of the aircraft, the two movements of compensation can be interchanged.

The corrective movements on the three axes are made continuously, individually. Thus, due to its rare frequency of occurrence, the yaw is treated individually, while the other two deviations (rolling and pitching) are treated together.

The camera is installed on a support through a gear, with the lens directed downward. This gear can be rotated within a range of $\pm 30^{\circ}$ around its axis by a toothed belt transmission, pinionandengine. This yaw compensation floor is mounted on a support plate [38].

The support plate is attached on one side to a box bearing, which materializes two axes of rotation:

- the rolling axis;

- the pitching axis

The support plate is driven simultaneously by the carriages of the two displacement-actuator systems, which consist of: guide, actuator, coupling, ball screw, carriage (Fig. 6).

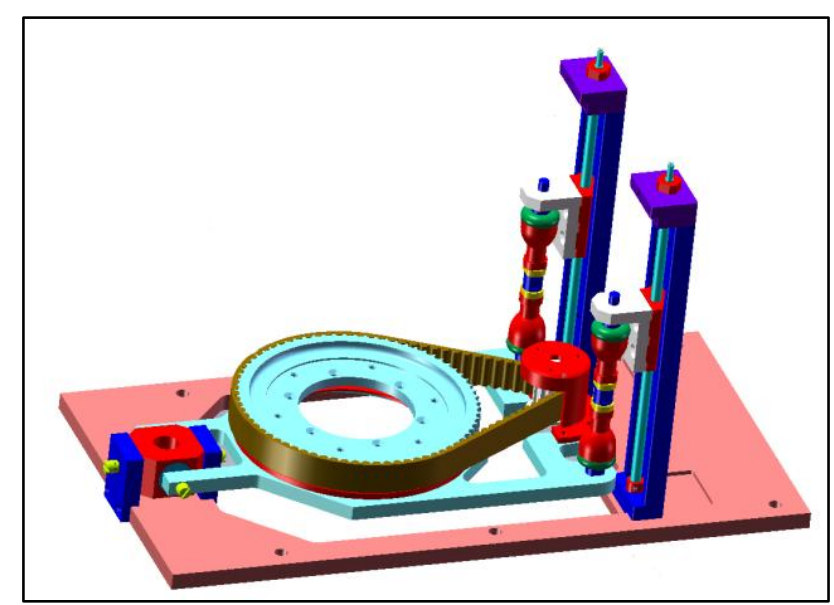

Fig.6. Platform operating systems [38] 
The base support secures the fastening of the operating system in the direction of the roll and the roll support (provided with a hinge), to enable the rotational movement of the MSTB around the first axis- which is the longitudinal axis of the plane [38].

On the rolling support, there are fastened the operating system in the pitching direction and the pitching support (provided with a hinge), to enable the MSTB rotational movement around the second axis which is the transverse axis of the plane.

The positioning sensors that are installed on the holding plate (MSTB) measure and transmit the information regarding the position of this plate (the MSTB position) related to the reference plane of the device.

The limitation of the movement made by the carriages performing the linear movement is ensured by the four sensors that are fastened by screws at the end of the linear movement strokes.

Depending on the received command, the two carriages of the linear operating systems can move simultaneously either in the same direction or in opposite directions. Their displacement leads to the rotation of the support plate around the transverse axis and thus to pitch correction.

The necessary compensations arising when the rectilinear motion is turned into a rotational motion, taking into account the small values of the angle of rotation, are provided by the spherical joints.

Figure 7 presents the linear motion system of the platform [38].

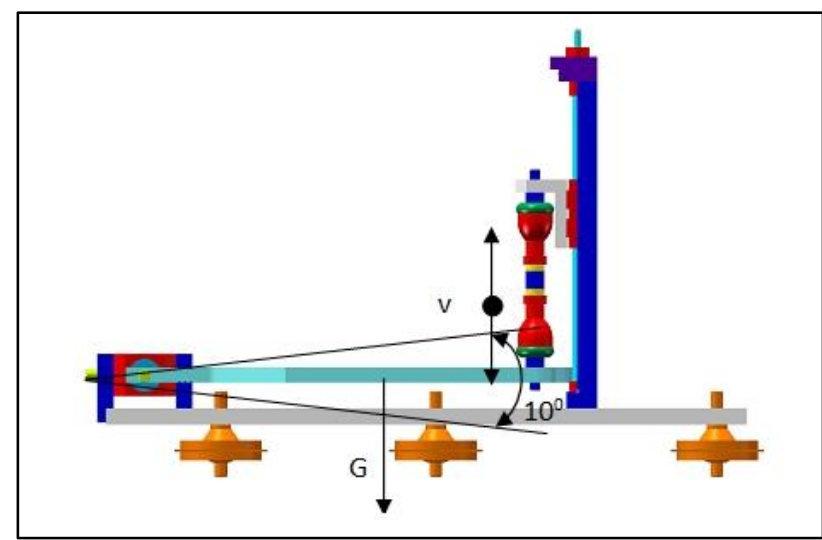

Fig. 7. The linear motion [38]

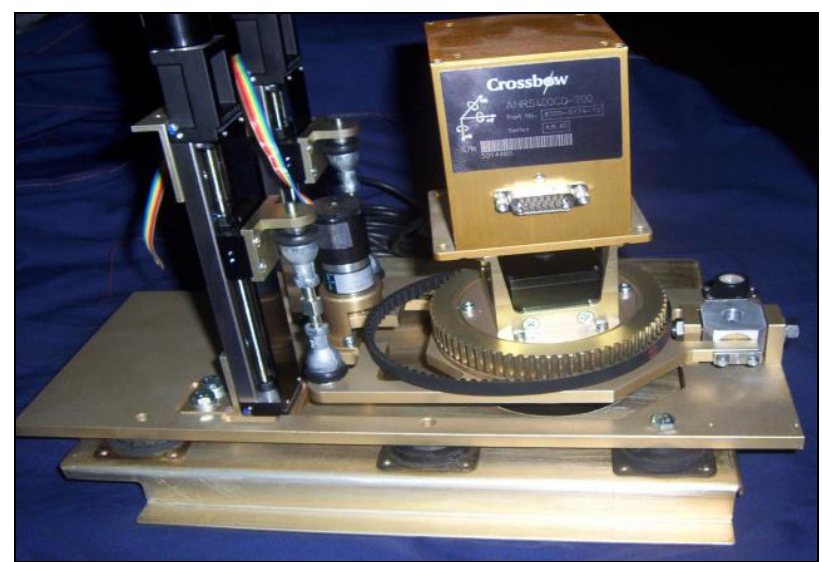

Fig. 8. Stabilizing platform [38]
The stabilizing platform (Fig. 8.) made by SC Aerostar S.A. Bacau has the followingtechnical characteristics [38]:

-Performance characteristics:

a.field angle compensation:

-rolling, for $0^{\circ} \operatorname{pitch} \pm 5^{\circ}$;

-pitching, for $0^{\circ} \operatorname{roll} \pm 5^{\circ}$;

$\bullet$ yaw $\pm 30^{\circ}$

b.accuracy of stabilization (repositioning):

-rolling, pitching $\quad 0.5^{\circ} \mathrm{rms}$;

•yaw $1^{\circ} \mathrm{rms}$

c.angular resolution

-rolling, pitching $<1^{\circ}$;

$\bullet$ yaw $<2 \circ$

d.angular velocity:

-rolling, pitching $\geq 5 \%$ sec;

•yaw $\geq 15 \%$ sec

e.angular acceleration:

-rolling, pitching $\geq 100 \% \mathrm{sec}^{2}$;

$\bullet$ yaw $\geq 15 \% \sec 2$.

f.durationofstabilization:

-rolling, pitching $\leq 1 \mathrm{sec}$.

$\bullet$ yaw $\leq 2 \mathrm{sec}$

g.payload:max $2.5 \mathrm{~kg}$

h.electric powerconsumption:

-25 W nominal / $36 \mathrm{~W}$ max din directcurrent mains $12 \mathrm{~V}$

-Physical characteristics:

a) Mass of theplatform $<5 \mathrm{Kg}$.

b) The overall dimensionsof the platformmust be correlatedwith the sizeof the spaceallocatedto the aircraft:

-lengthmax $300 \mathrm{~mm}$

-widthmax $300 \mathrm{~mm}$;

•heightmax $400 \mathrm{~mm}$

c) The electrical power supplysystem of the aircraftmust have the followingcharacteristics:

- type of power:DCvoltage;

- nominal value: $12.5 \mathrm{~V}$;

- voltagevariation: $10 \div 14.5 \mathrm{~V}$;

- maximum currentconsumption: $3 \mathrm{~A}$

d) The coolingsystemrequires - the system does not require additionalcoolingorventilationelements.

The stabilizing platform is installed near the mass center on the aircraft in order to eliminate interferences. (Fig. 9).

Gathering information on the deviations of the aircraft from normal flight conditions is provided by the inertial measurementunit. Offset correction orders for deviations are given by the supply and control unit (Fig. $10)$.

To identify the geographical position of the aircraft, a GPS antenna and a display monitor with its 
corresponding charts are used (Fig. 11).

\section{CONCLUSION}

Photogrammetry is an old concept, but it has recently undergone great changes in terms of data recording and processing technology.

Territorial cadastre is fast and efficient when photogrammetry is used.

The main equipment needed for aerial photogrammetry includes: an aircraft, a camera and a stabilizing platform.
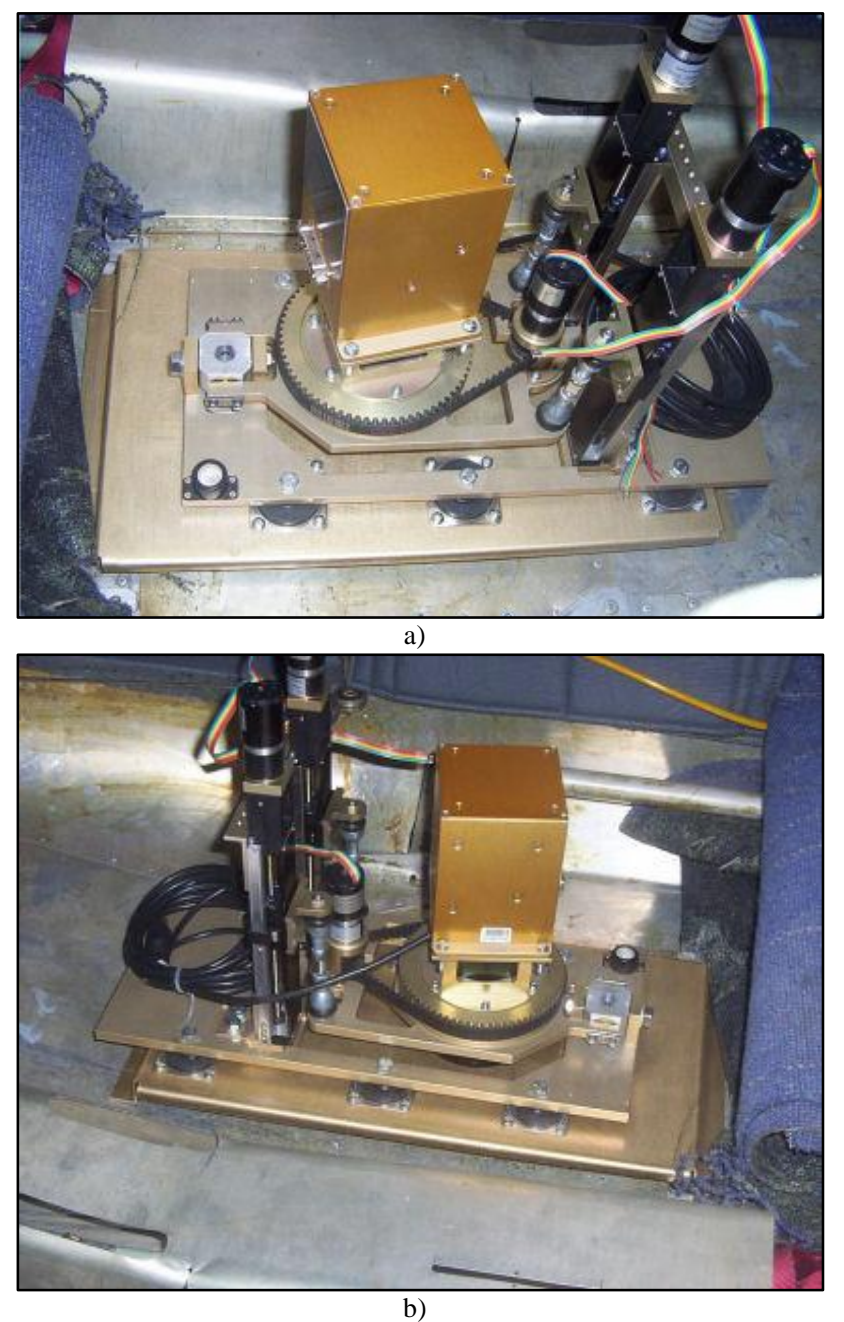

Fig. 9.Mounting the stabilizing platform on the aircraft [38]: a) image of stabilizing platform; $b$ ) position of stabilizing platform in aircraft

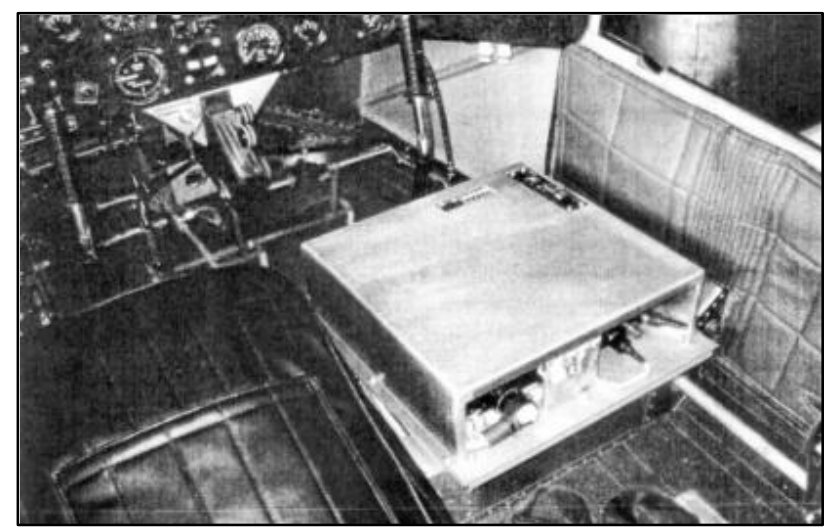

Fig.10.Setting up the control unit [38]
The main role of the stabilizing platform is to eliminate the disturbances produced by the aircraft (vibration, roll and / or pitch type oscillations) in order to obtainclearphotos.

This platform was designed and verified by S.C. Aerostar S.A. Bacau in collaboration with "VasileAlecsandri" University of Bacau. It is destined for the stabilizing of photogrammetry aerial platforms.

Thanks to its mechanical characteristics, the platform can take photos of an area according to the same system of coordinates.

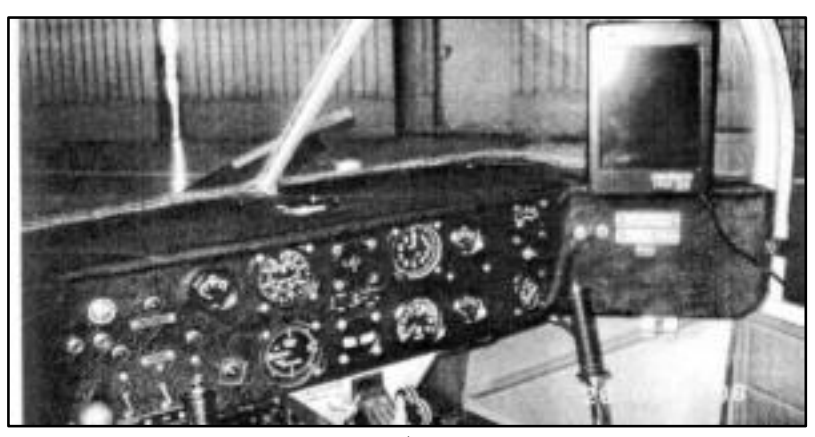

a)

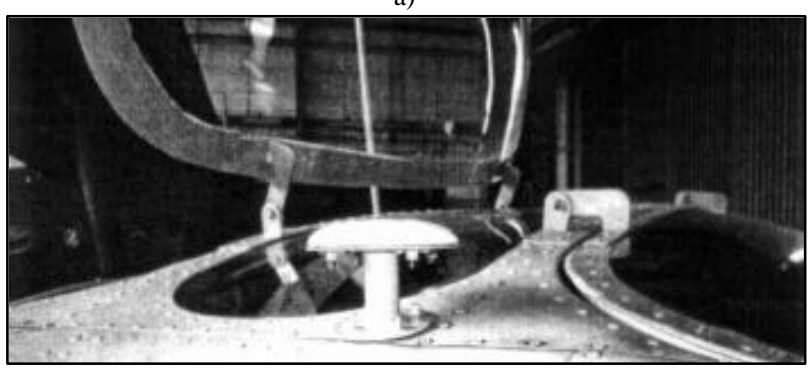

b)

Fig. 11. The Global Positioning System [38]:a) position display monitor, b) GPS antenna

One of the conditions to be fulfilled by the equipment installed on an aircraft is that it should have a reduced mass. In this respect, the designed platform has a mass of $5 \mathrm{~kg}$ and this does not affect the normal function of the aircraft that is used for photogrammetry. The three-axis platform was built by combining two stabilized platforms: a simple one for motion compensation on one axis (yaw) and a compound one for motion compensation on the other two axes (roll and pitch).

The design of the platform on three axes allows the system to perform compensating motions as related to the aircraft axis.

The compensating corrections of deviations are performed by the power and control unit, while the information regarding the deviations of the aircraft from normal flight conditions is provided by the inertial measurement unit.

Using a ball joint system allows the achievement of the compensation that is necessary when the rectilinear motion turns into a rotational motion.

The practical utility of the system resides in the fact that the corrective movements on the three axes can be performed both continuously and individually. 


\section{REFERENCES}

[1] Baumker, M.; Brechtken, R. \& Heimes, F.-J. (1999). Stabilized and directly georeferenced imagery based on INS/(D)GPS, Second International Symposium On Operationalization Of Remote Sensing, Itc Enschede, Netherlands

[2] Baumker, M.; Heimes, E.J.; Hahn, H.; Klier, W.; Brechtken, R.; Richter, T. (2000). Mathematicla modeling, computer simulation, control and applications of a stabilized platform of an airborne sensor, International Archives of Photogrammetry and Remote Sensing, vol. XXXII, patr. B2, Amsterdam

[3] Birdseye, C.H. (1940). Stereoscopic phototopographic mapping, Annals of the Association of American Geographers, Vol. XXX, No. 1, pp. 1-24

[4] Celestino, O.; Joaquin, M.; Pedro, A. \& Julia, A. (2010). Measuring building facades with a low-cost close-range photogrammetry system, Automation in Construction, Vol. 19, Issue 6, pp. 742-749

[5] Coulter, D. W.; Hauff, P. L. \& Kerby, W. L. (2007). Airborne Hyperspectral Remote Sensing, Proceedings of Exploration 07: Fifth Decennial International Conference on Mineral Exploration, edited by B. Milkereit, pp. 375-386

[6] Doyle, F. (1964). The Historical Development of Analytical Photogrammetry", Photogrammetric Engineering, Vol. XXX, No. 2, pp. 259-265.

[7] Dykes, J. A.; Moore, K. E. \& Fairbairn, D. (1999). From Chernoff to Imhof and Beyond: VRML and Cartography, Proceedings VRML 99: Fourth Symposium on Virtual Reality Modelling Language, pp. 99-104, New York

[8] Gorsevski, P.V. \& Gessler, P.E. (2009). The design and the development of a hyperspectral and multispectral airborne mapping system, Journal of Photogrammetry and Remote Sensing, vol. 64, pp. 184-192

[9] Haggrén, H. (2001). Fotogrammetrian erikoissovellutukset. Luento 8: Kuvaus- ja mittauskalusto, Available from: http://foto.hut.fi/opetus/260/luennot/6/6.html,Accessed on: 2006.10.25

[10] http://asapdata.arc.nasa.gov/Image.htm\#Platforms. The Sensor Facility image gallery presents a variety of images acquired by the Airborne Science Program since its inception in 1971, Accessed on: 2006.10 .27

[11] http://folk.uio.no/walmann/Publications/PhD/node47.html (1997). Stereo-photogrammetry, Accessed on: 2006.10.25

[12] http://luftbildarchiv.univie.ac.at/aerial-archaeology/dataacquisition/vertical-photography/, (2010). Vertical aerial photography, Accessed on: 2011.02.25

[13] http://luirig.altervista.org/enciclopediaonline/index.php?lemma=Camera. Camera, Accessed on: 2006.10.26

[14] http://strategia.ncsd.ro/docs/sndd-final-ro.pdf (2008). Strategia $\mathrm{Na}$ ionala pentru Dezvoltare Durabila a României Orizonturi 2013-2020-2030, Accessed on: 2011.11.09

[15] http://www.aeroflex.com/products/motioncontrol/gimbal.cfm. Gimbal Systems and Controllers, Accessed on: 2006.10.25

[16] http://www.airforce-technology.com/contractors/surveillance /controp/controp1.html, (2012). CONTROP - Electro-Optical and Precision Motion Control Systems, Accessed on: 2010.08.22

[17] http://www.esa.int/esaCP/SEMUQWWO4HD_Austria_1.html, (2003).ESA Lokale Nachrichten Österreich, Accessed on: 2006.10.26

[18] http://www.esw-wedel.de/download/stabilized_aircraft_e.pdf (2011), Gimbal subassembly for uav ground station, Accessed on: 2010.11.14

[19] http://www.fh-bochum.de/fb5/photo/projekte/leo/LEO_Prospekt _Englisch_DGPF2003.pdf, (2003). Fachhochschule Bochum, Accessed on: 2006.10 .26

[20] http://www.geometrics-gps.com (1997). Photogrammetry, Accessed on: 2006.10.31

[21] http://www.idealaerosmith.com/motion/hydraulic fms_systems.aspx, (2002). Hydraulic Flight Motion Simulation (FMS) Systems, Accessed on: 2006.10 .25

[22] http://www.innovisionoptics.com/news/news7.shtml, (02/01/2001).Innovision-Optics presents the new ROLLVISION Wireless Gyro-Stabilized Camera System, Accessed on: 2006.10.25
[23] http://www.photogrammetry.ethz.ch/research/TLS/TLS_Overvie w.html

[24] http://www.sagebrushtech.com/gim-gloss.php, 101, Accessed on: 2006.10.31

[25] http://www.sagebrushtech.com/prod-model2.php, 2006.10.25

[26] http://www.sagebrushtech.com/prod-model30w.php Model 30 Worm Drive, Accessed on: 2010.07.12

[27] http://www.sagebrushtech.com/prod-modelaero20.php, (2005) Model Aero 20, Accessed on: 2006.10.25

[28] Jaime, R.; Maria, T. M.; Pedro, A.; Celestino, O. \& Jose, H. (2008). Flatelements on building susing close - range photogrammetry and laser distance measurement, Optics and Lasers in Engineering, vol. 46, pp. 541- 545

[29] Jiang, H., Jia, H., Wei, Q. (2011). Analysis of zenith pass problem and tracking strategy design for roll-pitch seeke, Aerospace Science and Technology

[30] Koch, M \& Kaehler, M. (2010). Combining 3D Laser-Scanning and Close-Range Photogrammetry - An Approach to Exploit the Strength of Both Methods, Journal Of Theoretical And Applied Mechanics, vol. 48, no. 1, pp. 5-26

[31] Konecny, G. (1985). The International Society for Photogrammetry and Remote Sensing-75 Years Old, or 75 Years Young, Keynote Address, Photogrammetric Engineering and Remote Sensing, vol. 51, no. 7, pp. 919-933

[32] Krumpen, T.; Haas, C.; Hendricks, S.; Hölemann, J. A. ; Kalmbach, D. \& Gerdes, R. (2011). HELIOS, a nadir-looking sea ice monitoring camera, Cold Regions Science and Technology, vol. 65 , pp. 308-313

[33] Luhmann, T. (2010). Close range photogrammetry for industrial applications, Journal of Photogrammetry and Remote Sensing, vol. 65 , pp. 558-569

[34] Manfred, B.R.; Rainer, B.N; Heimes, F.J. (16 - 20 August 1999). Stabilized and directly georeferenced imagery based on INS/(D)GPS, Second International Symposium On Operationalization of Remote Sensing, ITC Enschede, Netherlands, Available from: http://www.hochschulebochum.de/fileadmin/media/fb_v/labore/photogrammetrie/Artikel /Veroeffentlichungen/Paper_ITC_082001.pdf

[35] Oprescu, N. (1961). Fotogrametrie. Apliaţiile fotogrametriei, E.D.P., Bucureşti

[36] Pesci, A.; Fabris, M.; Conforti, D.; Loddo, F.; Baldi, P.; Anzidei, M. (2007). Integration of ground-based laser scanner and aerial digital photogrammetry for topographic modelling of Vesuvio volcano, Journal of Volcanology and Geothermal Research, vol. 162 , pp. $123-138$

[37] Photogrammetry applications in digital terrain modeling and floodplain mapping [online]. Austin, Texas: The University of Texas at Austin, (1998). www.ce.utexas.edu/prof/maidment/grad/tate/study/remote/TermPr oj.html, Accessed on: 25.10 .2006

[38] Research contract CEEXno. 112/2006. Microplatformă stabilizată pentru echipamente video de supraveghere aeriană - MSTB

[39] Reulke, R. (2003). Film-based and digital sensors - Augmentation or change in paradigm?, Wichmann Verlag, Available from: http://www.ifp.uni-stuttgart.de/publications/phowo03/reulke.pdf, Accessed: 2006.10 .27

[40] Suveg, I. \&Vosselman, G. (2004). Reconstruction of 3D building models from aerial images and maps, Journal of Photogrammetry \& Remote Sensing, vol. 58, pp. 202-224

[41] Wei, Ji; Qi, Li; Bo, Xu; Dean, Zhao \& Shixiong, Fang. (JanuaryFebruary 2011). Adaptive fuzzy PID composite control withhy steresis-bands witching for line of sight stabilization servo system, Aerospace Science and Technology, vol. 15, Issue 1, pp. 25-32

[42] Zbigniew, K. (2011). The numerical analysis of dynamics and control of gyroscopic scanning system in an anti-aircraft missile laungher, Communications in Nonlinear Science and Numerical Simulation, vol. 16, Issue 5, pp. 2230-2236

[43] Zebedin, L.; Klaus, A.; Gruber-Geymayer, B. \& Karner, K (2006). The Short Wave Aerostat-Mounted Imager (SWAMI): A novel platform for acquiring remotely sensed data from a tethered balloon, Remote Sensing of Environment, vol. 103, pp. 255 - 264 